\title{
Arelige Ongigal
}

\section{EFETTOS DE OPERAÇÕES SOBRE 0 BAÇO NO LIPIDOGRAMA DE RATAS}

\author{
Andy Petroianu*, Denny Fabrício Magalhães Veloso, Gustavo Rocha Costa, Luiz Ronaldo Alberti
}

Trabalho realizado no departamento de Cirurgia, Faculdade de Medicina da Universidade Federal de Minas Gerais, Belo Horizonte, MG

\author{
*Correspondência: \\ Andy Petroianu \\ Av. Afonso Pena, $\mathrm{n}^{\circ} 1626$, \\ Apto 1901. \\ CEP 30130-005, Belo \\ Horizonte, Minas Gerais. \\ Fone/Fax: (31) 3274-7744 \\ petroian@medicina.ufmg.br
}

\begin{abstract}
RESUMO
Objetivo. Apesar de serem bem estabelecidas as alterações esplênicas nas dislipidemias, como a doença de Gaucher, ainda não se estudou adequadamente a relação do baço com o metabolismo lipídico. Com vista a contribuir para preencher esse hiato, a presente investigação avaliou experimentalmente o lipidograma na presença do baço, em asplenia e após operações conservadoras desse órgão.
\end{abstract}

Métodos. Foram utilizadas 50 ratas Wistar de pesos e idades semelhantes distribuídas em quatro grupos: Grupo I- controle, com baço íntegro; Grupo 2 - laparotomia e laparorrafia, Grupo 3 - esplenectomia total; Grupo 4 - esplenectomia subtotal e Grupo 5 - esplenectomia total complementada por implantes de tecido esplênico autógeno. Após quatro meses, foram dosados os níveis séricos de triglicérides, colesterol total e suas frações VLDL, LDL, HDL. Os resultados dos quatro grupos foram comparados entre si pela análise de variância, seguida pelo teste de Tukey-Kramer, com significância para $p<0,05$. Resultados. Não houve diferença entre os grupos 1, 2, 3 e 4. Nos animais submetidos a esplenectomia total, as concentrações de colesterol total $(p=0,015 \mathrm{I})$ e de sua fração $L D L(p<0,000 \mathrm{I})$ foram maiores, enquanto a fração HDL foi menor $(p=0,0026)$ do que as encontradas nos demais grupos. Não houve diferença entre os grupos com relação aos triglicérides $(p=0,157 \mid)$ e VLDL $(p=0,2527)$.

Conclusões. É provável que o baço desempenhe um papel de destaque no metabolismo lipídico de ratas e que a esplenectomia total se relacione com alterações no controle do colesterol. É possível que a preservação de tecido esplênico previna tais distúrbios metabólicos.

UnITERMOS: Baço. Esplenectomia. Esplenectomia subtotal. Auto-implante esplênico. Colesterol. Triglicérides.

\section{INTRODUÇÃo}

As funções do baço fazem parte do metabolismo orgânico e distúrbios desse órgão relacionam-se com diferentes doenças ${ }^{1-10}$. Afecções nos depósitos lisossômicos são consideradas as alterações metabólicas mais freqüentemente associadas a um defeito enzimático que envolva o baço. Na doença de Gaucher, por exemplo, o acúmulo de glicocerebrosídeos nos lisossomos das células do sistema reticuloendotelial leva à formação de células carregadas de lípides conhecidas como células de Gaucher. Esse acúmulo de glicocerebrosídeos nos macrófagos do baço e nas células de Kupffer do fígado provoca aumento desses órgãos. Além disso, outras esfingoliposes, tais como a doença de Niemann-Pick, as gangliosidases e a doença de Faber também apresentam manifestações esplênicas ${ }^{10}$. $\mathrm{O}$ baço participa do metabolismo de todos os metais, dos albuminóides e da bilirrubina indireta, a partir das hemácias fagocitadas ${ }^{11,12}$.

Pacientes portadores de doenças mieloproliferativas (policitemia vera e mielofibrose) acompanhadas de metaplasia mielóide e de hiperesplenismo cursam com esplenomegalia e apresentam diminuição dos valores de colesterol total, HDL, apolipoproteína B e apolipoproteína A-I. Nessas doenças, a esplenectomia normaliza os valores dessas substâncias ${ }^{2,7,13}$.

Há uma evidente e comprovada relação entre dislipidemia e doenças vasculares, em especial aterosclerose, que é responsável por elevada morbi-mortalidade na população geral. Fatouros et al. (1995) observaram que pessoas esplenectomizadas por trauma apresentavam maior incidência de coronariopatias por aterosclerose decorrente, provavelmente, de distúrbios lipídicos ${ }^{2}$. As alterações no metabolismo lipídico em decorrência da esplenectomia por trauma poderiam eventualmente explicar a alta incidência de infarto agudo do miocárdio relatada em veteranos da Segunda Guerra Mundial'4.

Algumas pesquisas experimentais relacionam a influência do baço no metabolismo das gorduras. King, em 19|4, verificou aumento do colesterol em cães, após a remoção esplênica ${ }^{15}$. Asai et al. ${ }^{4}$, observaram que coelhos que se alimentavam de produtos com altos níveis de colesterol tinham aumento de colesterol, triglicérides, fosfolípides, e baixos níveis de HDL, após a retirada do baço. Esse fato foi também relatado em ratos com alimentação enriquecida com colesterol?

Apesar da ampla documentação na literatura sobre as dislipidemias, ainda são muito poucos e controversos os trabalhos que correlacionaram o baço e o efeito das operações esplênicas conservadoras no metabolismo lipídico. Diante desse hiato, o presente trabalho avaliou experimentalmente a influência do baço e de diferentes operações realizadas sobre ele, assim como do auto-implante esplênico no lipidograma.

\section{Métodos}

O presente trabalho foi realizado de acordo com as recomendações das Normas Internacionais de Proteção aos Animais e do Código Brasileiro de Experimentação Animal (1988) e foi aprovado pela Comissão de Ética do Departamento de Cirurgia da Faculdade de Medicina da Universidade Federal de Minas Gerais (UFMG) ${ }^{16,17}$.

Foram utilizadas 40 ratas Wistar com peso médio de $133 \pm 19$ 


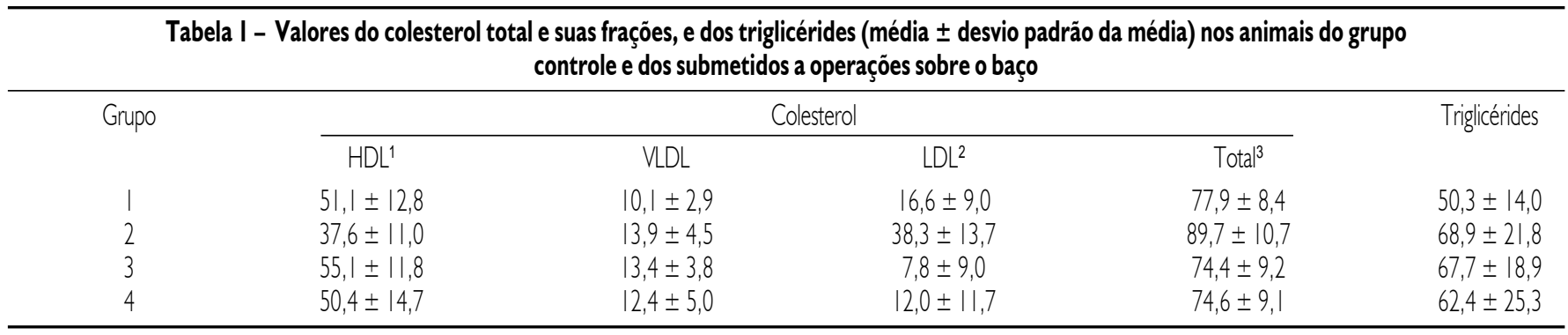

Grupo I: Controle

Grupo 2: Esplenectomia total

Grupo 3: Esplenectomia subtotal

Grupo 4: Esplenectomia total + auto-implante esplênico

I: $\mathbf{p}=\mathbf{0 , 0 5}$ (Grupo 2 em relaçãa aos demais grupos)

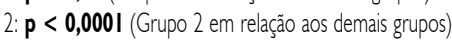

3: $\mathbf{p}=\mathbf{0 0 9 3}$ (Grupo 2 em relação aos demais grupos)

gramas, procedentes do Biotério do Instituto de Ciências Biológicas da UFMG e mantidas no Biotério da Faculdade de Medicina da UFMG.

Os animais foram alocados em gaiolas apropriadas, com até cinco ratas por gaiola, à temperatura ambiente de $25^{\circ} \mathrm{C}$ e iluminação diária natural. Elas receberam água e ração balanceada padrão para ratos à vontade. Antes do experimento, as ratas foram submetidas a exame para descartar possíveis afecções, durante o período de adaptação de I5 dias. Os animais foram distribuídos aleatoriamente nos seguintes grupos:

Grupo I $(n=10)$ - Controle: não foram submetidos a intervenção cirúrgica.

Grupo 2 ( $n=10)$ - Esplenectomia total: o estômago foi tracionado para fora da cavidade abdominal, expondo o baço. Em seguida, foram realizadas três ligaduras do pedículo vascular esplênico com fio de categute cromado 5-0 e retirada completa do órgão.

Grupo $3(n=10)$ - Esplenectomia subtotal: ligadura vascular do baço com fio de categute cromado 5-0, deixando apenas o pólo superior suprido pelos vasos esplenogástricos, secção do baço entre as partes isquêmica e irrigada. Sutura contínua da superfície cruenta do pólo esplênico superior com fio de categute cromado 5-0.

Grupo $4(\mathrm{n}=10)$ - Esplenectomia total complementada por implante de tecido esplênico autógeno no omento maior. Após a retirada do baço, seguindo as etapas descritas no Grupo 2, fatiou-se o órgão em 5 segmentos que foram suturados sobre o omento maior, com fio de categute cromado 5-0.

Todos os procedimentos foram realizados nas dependências do Laboratório de Cirurgia Experimental do Departamento de Cirurgia da Faculdade de Medicina da UFMG, obedecendo às normas técnicas de assepsia e anti-sepsia.Todos os procedimentos operatórios foram conduzidos sob anestesia geral com éter etílico e através de laparotomia mediana, de aproximadamente $4 \mathrm{~cm}$, iniciada $0,5 \mathrm{~cm}$ abaixo do apêndice xifóide, no sentido crânio-caudal. A cavidade abdominal das ratas foi fechada em dois planos de sutura contínua (no primeiro, o peritônio e plano músculo aponeurótico e, no segundo, a pele), utilizando fio de algodão 5-0.

As ratas foram acompanhadas diariamente durante 120 dias. Decorrido esse prazo, elas foram anestesiadas com éter etílico e submetidas a laparotomia mediana. Identificou-se a veia cava caudal, que foi puncionada sob sistema de coleta a vácuo, no qual se coletaram $5 \mathrm{ml}$ de sangue em tubos com gel e revestidos com papel alumínio para proteção da luz, que foram imediatamente enviados para análise laboratorial. Após a centrifugação a 2000 rpm por 5 minutos, do plasma separado dosaram-se as concentrações de triglicérides, colesterol total e HDL pelo método colorimétrico enzimático. As concentrações das frações do colesterol VLDL e LDL foram calculadas pela fórmula de Friedwald. Em seguida, os animais foram mortos com dose inalatória letal de éter.

Os valores de colesterol total e suas frações e de triglicérides foram avaliados nos diferentes grupos pelo teste de Normalidade de Kolmogorov-Smirnov (KS) para testar a distribuição gaussiana dos dados e, em seguida, pelo teste de Bartlett para testar as variâncias. Caso os dados apresentassem distribuição gaussiana e mesma variância, realizava-se a análise de variância (ANOVA), seguida pelo teste de Tukey-Kramer de comparação múltipla. Os valores foram considerados significativos para $p<0,05$.

\section{Resultados}

No Grupo 2, dos animais esplenectomizados, houve três mortes na primeira semana pós-operatória, sem causa aparente ao exame macroscópico da cavidade abdominal. Esses animais foram substituídos para manter a uniformidade do número de animais em cada grupo. Não foram verificadas adversidades nos outros grupos. Os animais recuperaram-se rapidamente do procedimento cirúrgico.

Todas as dosagens de colesterol total apresentaram valores com distribuição dentro da curva normal $(p>0,10)$ (distância KS de 0, 1572 para o Grupo I, KS de 0,3355 para o Grupo 2, KS de 0, 1396 para o Grupo 3 e KS de 0,1949 para o Grupo 4). As variâncias não foram diferentes ( $p=0,9325$, pelo teste de Bartlett). Os animais submetidos a esplenectomia total (Grupo 2) apresentaram maiores concentrações de colesterol total ( $p=0,0093$ ANOVA) em relação aos demais grupos. Não houve diferença entre os outros grupos (Tabela I).

As dosagens da fração VLDL do colesterol apresentaram valores com distribuição dentro da curva normal $(p>0,10)$ (distância KS de 0,2। 40 para o Grupo I, KS de 0,227I para o Grupo 2, KS de 0, 1822 
Petrolanu A et al.

para o Grupo 3 e KS de 0,2800 para o Grupo 4). As variâncias não foram diferentes ( $p=0,4665$, pelo teste de Bartlett). Não houve diferença com significância estatística entre os grupos ( $p=0,2030$, ANOVA) (Tabela I).

As dosagens da fração LDL do colesterol apresentaram valores com distribuiç̧ão dentro da curva normal $(p>0,10)$ (distância KS de 0,2। 42 para o Grupo I, KS de 0,2065 para o Grupo 2, KS de 0,29I2 para o Grupo 3 e KS de 0,1967 para o Grupo 4). As variâncias não foram diferentes $(p=0,611 \mathrm{l}$, pelo teste de Bartlett). Os animais submetidos a esplenectomia total (Grupo 2) apresentaram maiores concentrações de colesterol LDL $(p<$ 0,0001 ANOVA) em relaçãa aos demais grupos. Não houve diferença entre os outros grupos (Tabela I).

As dosagens da fração HDL do colesterol apresentaram valores com distribuição dentro da curva normal $(p>0,10)$ (distância KS de 0, I 900 para o Grupo I, KS de 0,34I 6 para o Grupo 2, KS de 0,2034 para o Grupo 3 e KS de 0, 1690 para o Grupo 4). As variâncias não foram diferentes ( $p=0,8927$, pelo teste de Bartlett). A fração HDL do grupo submetido a esplenectomia total (Grupo 2) foi menor do que a registrada nos demais grupos $(p=0,05$, ANOVA). Não houve diferença significativa entre os outros grupos (Tabela I).

As dosagens de triglicérides também apresentaram valores com distribuição dentro da curva normal ( $p>0,10)$ (distância KS de 0,2370 para o Grupo I, KS de 0,2352 para o Grupo 2, KS de 0, I776 para o Grupo 3 e KS de 0,2559 para o Grupo 4). As variâncias não foram diferentes ( $p=0,4310$, pelo teste de Bartlett). Não houve diferença entre os grupos estudados ( $p=0,1882$, ANOVA) (Tabela I).

\section{Discussão}

O baço destaca-se na prática médica em decorrência de suas atribuições, parcialmente já bem conhecidas, como o seu papel imunitário, de filtração e hematopoiético ${ }^{18}$. Além dessas funções, a sua participação no controle metabólico vem merecendo uma atenção crescente $1,2,3,4,5,6,7,7,9$. Sua importância na fisiopatologia de muitas doenças fez com que se optasse pela preservação desse órgão, reduzindo os índices de sepse e distúrbios hematológicos pós-operatórios ${ }^{19}$. A esplenectomia total, que resultava de muitas indicações no passado, vem sendo progressivamente substituída por procedimentos conservadores do baço, como a sutura esplênica, a esplenectomia parcial, a esplenectomia subtotal ou o implante autógeno de tecido esplênico, após a remoção do baço $18,20,21,22,23$. Mais recentemente, passou a ser bem aceita a abordagem não operatória do trauma esplênico, com resultados melhores do que os operatórios ${ }^{24}$.

Existem, na literatura, trabalhos clínicos e experimentais que avaliaram a possível relação entre o baço e o metabolismo lipídico no hiperesplenismo $1,2,3,6,7,8 \mathrm{e}$ em presença de asplenia $1,2,5,7,9$. Gilbert et al. (|98|) descreveram decréscimo nos níveis séricos de colesterol total e de suas frações LDL e HDL em pacientes portadores de doenças mieloproliferativas associadas a hiperesplenismo ${ }^{8}$. Nos períodos de agravamento da doença de base, havia redução ainda maior dos níveis de colesterol. Após esplenectomia total ou quando a moléstia era controlada por agentes quimioterápicos ou com irradiação esplênica, ocorreu a reversão da hipocolesterolemia ${ }^{8}$. Outros autores também analisaram essa relação em pacientes portadores da doença de Gaucher tipo $1^{6} \mathrm{e}$ talassemia maior tipo $B^{3}$, tendo sido encontrados resultados semelhantes.

Por outro lado, em estudos experimentais, a esplenectomia total acompanhou-se de níveis elevados de colesterol e triglicérides 2,4.5. Aviram et al. (1986) notaram que, após esplenectomia para tratar desordens mieloproliferativas, houve elevação da fração LDL do colesterol ${ }^{7}$.

A dislipidemia secundária à esplenectomia total poderia resultar em maior incidência de distúrbios ateroscleróticos ${ }^{25,26,27,28,29}$. Na tentativa de estabelecer essa relação, Asai et al. (1988) observaram que coelhos submetidos a esplenectomia total e que receberam alimentação rica em colesterol apresentaram, após quatro meses, placas ateroscleróticas na aorta ${ }^{5}$.

Existem algumas teorias para explicar os possíveis mecanismos implicados na regulação dos lípides plasmáticos pelo baç̧ 1,3,5,6,7. Schmidt et al. (1997) compararam o baço a um reservatório lipídico, que se eleva em situações de hiperesplenismo. Os macrófagos esplênicos acumulariam grande quantidade de gordura, mediante aumento da fagocitose com conseqüente hipolipidemia'. Outra explicação para a redução lipídica seria o efeito imunitário do sistema mononuclear fagocitário contra estruturas encontradas nas lipoproteínas HDL e LDL, resultando em sua depuraçãa plasmática 3,6.

Com base nessas teorias, após a esplenectomia total, o efeito inverso provocaria o aumento dos níveis séricos dos lípides plasmáticos. Entretanto, há necessidade de prosseguir a investigação desse fenômeno para comprovar a veracidade dessas hipóteses e aprofundar suas explicações.

O presente trabalho também encontrou a elevação do colesterol total e de sua fração LDL. Por outro lado, a fraçãa HDL apresentou concentração menor. Já os níveis de triglicérides e de VLDL foram inalterados, assim como havia sido descrito por Aviram et al. ${ }^{7}($ (986) e contradizendo outros autores ${ }^{2,4,5}$.

É importante ressaltar que as cirurgias conservadoras do baço mantiveram o lipidograma em seus níveis normais. Portanto, a presença de tecido esplênico, mesmo em quantidade menor e até ectópico, é capaz de manter funções do órgão relacionadas à regulação do metabolismo lipídico. Além disso, considerando-se a hipótese de que a irrigação sangüínea do omento seria menos propícia que a irrigação própria do baço, diminuindo a funcionalidade do órgão, não houve diferenças no lipidograma do Grupo 4 em relação aos grupos I e 3.

\section{Conclusões}

É provável que o baço desempenhe um papel de destaque no metabolismo lipídico de ratas e que a esplenectomia total se relacione com alterações no controle do colesterol. É posśivel que a preservação de tecido esplênico previna tais distúrbios metabólicos.

\section{Agradecimentos}

Os autores agradecem o auxilio da Dra. Renata Figueiredo Rocha pela apresentação deste trabalho e ao CNPq e à FAPEMIG pelos auxilios financeiros.

Conflito de interesse: não há. 


\section{SUMMARY}

\section{EFFECTS OF SPLENIC SURGERIES ON LIPIDOGRAM OF RATS}

BACKGROUND. Although the occurrence of spleen alterations in the various forms of dyslipidemia, such as Gaucher's disease, has been well established, the relation between the spleen and lipid metabolism has not been properly studied. In order to contribute to the filling of this gap, in the present investigation we assessed experimentally the lipidogram of rats in the presence of the spleen, in asplenia, and after conservative spleen surgeries.

METHODS. Forty female Wistar rats of similar weight and age were divided into 4 groups submitted to the following procedures: Group Icontrol, with an intact spleen; Group 2 - total splenectomy; Group 3 subtotal splenectomy, and Group 4 - total splenectomy complemented with autogenous spleen tissue implants. Four months after the interventions, serum triglycerides, total cholesterol and fractions (VLDL, $L D L, H D L)$ were determined. The results for the four groups were compared by analysis of variance followed by the Tukey-Kramer test, with the level of significance set at $p<0.05$.

RESULTS. There were no differences between groups I, 3 and 4 . In the animals submitted to total splenectomy, total cholesterol ( $p=0.0093$ ) and $L D L$ fraction concentrations $(p<0.0001)$ were higher, whereas $H D L$ fraction concentrations were lower $(p=0.05)$ than those detected in the other groups. There was no difference in triglycerides $(p=0.1882)$ or $\operatorname{VLDL}(p=0.2030)$ between groups.

CONCLUSIONS. The spleen probably plays an important role in the lipid metabolism of female rats and total splenectomy may be related to changes in cholesterol control. It is possible that preservation of spleen tissue prevents such metabolic disorders. [Rev Assoc Med Bras 2006; 52( I): 56-9]

KeY Words: Spleen. Splenectomy. Partial splenectomy. Splenic autoimplants. Cholesterol. Triglycerides.

\section{REFERÊNCIAS}

I. Schmidt HH, Wagner S, Manns M. The spleen as a storage pool in lipid metabolism. Am J Gastroenterol 1997; 92: 1072-2.

2. Fatouros M, Bourantas K, Bairaktari E, Elisaf M, Tsolas O, Cassioumis D. Role of the spleen in lipid metabolism. Br J Surg 1995; 82: 1675-7.

3. Goldfarb AW, Rachmilewitz EA, Eisenberg S. Abnormal low and high density lipoproteins in homozygous beta-thalassaemia. $\mathrm{Br} J$ Haematol 1991; 79: 48I-6.

4. Asai K, Hayashi T, Kuzuya M, Funaki C, Naito M, Kuzuya F. Delayed clearance of beta-very low density lipoprotein after feeding cholesterol to splenectomized rabbits. Artery 1990; 18: 32-46.

5. Asai K, Kuzuya M, Naito M, Funaki C, Kuzuya F. Effects of splenectomy on serum lipids and experimental atherosclerosis. Angiology 1988; 39: 497504.

6. Le NA, Gibson JC, Rubinstein A, Grabowski GA, Ginsberg HN. Abnormalities in lipoprotein metabolism in Gaucher type I disease. Metabolism 1988; 3: 240-5.

7. Aviram M, Brook JG, Tatarsky I, Levy Y, Carter A. Increased lowdensity lipoprotein levels after splenectomy: a role for the spleen in cholesterol metabolism in myeloproliferative disorders. Am J Med Sci 1986; 291: 25-8

8. Gilbert HS, Ginsberg H, Fargerstrom R, Brown WV. Characterization of hypocholesterolemia in myeloproliferative disease. Relation to disease manifestations and activity. Am J Med 1981; 71: 595-602.

9. Bednarik T, Cajthamlova H. Serum proteins after splenectomy in dog, the rabbit and the rat. Physiol Bohemoslov 1968; 17: 249-52.

10. Viana MB, Oliveira BM, Oliveira MCLA. O Baço em doenças metabólicas. In: Petroianu A, editor. O Baço. I ed. São Paulo: CLR Baliero Editores; 2003, p. 197-205.

II. Constantopoulos A, Najar VA, Wisch JB, Necheles TH, Stolbach LL: Defective phagocytosis due to tuftsin deficiency in splenectomized subjects. Am J Dis Child 1973; 125: 663-5.

12. Petroianu A. Estudos experimentais sobre o baço. In: Petroianu A, editor. O Baço. I ed. São Paulo: CLR Baliero Editores; 2003, p.4I4-26.

13. Sugihara T, Yawata Y. Observations on plasma and red cell lipids in hereditary spherocytosis. Clin Chim Acta 1984; 137: 227-32.

14. Paulo DNS, Lázaro da Silva A. Lipídeos plasmáticos após esplenectomia total e parcial em cães. Rev Col Bras Cir 200 I : 28: 264-70.

15. King JH. Studies in the pathology of the spleen. Arch Intern Med I 9 | 4; I 4: 145-67.

16. Cooper JE. Ethics and laboratory animals. Vet Rec 1985; I | 6: 594-5.

17. Petroianu a Pesquisa experimental. In: Petroianu A, editor. Ética, Moral e Deontologia Médicas. Rio de Janeiro: Guanabara Koogan; 2000, p. 185-90.

18. Petroianu A. Cirurgia do baço. In: Petroianu A, editor. Clínica Cirúrgica. Rio de Janeiro: Revinter; 200I, p.429-42.

19. Morris DH, Bullock FD. The importance of the spleen in resistance to infection. Ann Surg 1919; 70: 513-21.

20. Morgenstern L. Evolution of splenic surgery. Contemp Surg 1986; 29: 15-8.

21. Morgenstern L. Techniques of splenic conservation. Arch Surg 1979; | | 4: 449-54.

22. Traub A, Giebink GS, Smith C. Splenic reticuloendothelial function after splenectomy, spleen repair and spleen autotransplantation. N Engl J Med 1987; 317:1559-64.

23. Times $W$, Leemans R: Splenic autotransplantation and the immune system. Ann Surg 1992; 21 5: 256-60.

24. Albrecht RM, Schermer CR, Morris A. Nonoperative management of blunt splenic injuries: Factors influencing success in age $>55$ years. Am Surg 2002; 68: 227-31.

25. Witztum JL, Steinberg D: As hiperlipoproteinemias. In: Cecil, editor. Tratado de Medicina Interna. $21^{a}$ Edição. Rio de Janeiro: Guanabara Koogan; 2001, p. 1212-24.

26. Mahley RW, Weisgraber KH, Farese RV. Disorders of lipid metabolism. In: Williams, editor. $9^{\text {th }}$ edition. United States: W.B.Saunders Company; 1998, p. 1099-153.

27. Assmann G, Schulte H. Relation of high-density lipoprotein cholesterol and triglycerides to incidence of atherosclerotic coronary artery disease. Am J Cardiol 1992; 70: 733-7.

28. Gordon DJ, Rifkind BM. High-density lipoprotein. The clinical implications of recent studies. N Engl J Med 1989; 32 I: I3 | I-6.

29. Kinosian B, Glick H, Garland G. Cholesterol and coronary heart disease: predicting risks by levels and ratios. Ann Intern Med 1994; 121: 641-7. 